\title{
Evaluation of Micro Tuberization Performances of Different Genotypes
}

\author{
Ayten Kübra Türkmen*, Caner Yavuz, Sarbesh Das Dangol, Cehibe Tarım, Ufuk Demirel, \\ Mehmet Emin Çalışkan
}

Ömer Halisdemir University, Faculty of Agricultural Sciences and Technologies, Department of Agricultural Genetic Engineering, 51240 Niğde, Turkey

A R T I C L E I N F O

Research Article

Received 26 October 2016

Accepted 22 January 2017

Keywords:

Micro tuber

Seed potato

In vitro culture

Genotype

Potato

${ }^{*}$ Corresponding Author:

E-mail: aytenkubraturkmen@gmail.com \begin{abstract}
A B S T R A C T
Certified potato seed tuber usage is one of the most important steps for production of high yield and quality potatoes. For this reason different seed tuber production methods have been developed. Among these methods, mini tuber production is the most popular one. In order to produce mini tubers, firstly potato plants are produced in vitro, and these plants are transferred to an environmentally-controlled greenhouse. Thus, disease- and virusfree mini tubers are produced as seed tubers. However, in vitro section of mini tuber production creates problems like storage and transfer of in vitro plants, and adaptation period of the plants to greenhouse conditions. In vitro micro tuber (MT) formation has been selected as a solution of these problems. The aim of the study was to produce micro tubers from 15 different genotypes and evaluate their micro tuberization performances to determine the genotype effect on MT formation. 3 varieties, 3 breeding lines and 9 different genotypes from International Potato Center (CIP) were selected for the study. For this purpose, micro tubers are produced in vitro by using Murashige and Skoog (MS) medium supplemented with $8 \%$ sucrose and $0.1 \mathrm{mg} / \mathrm{L}$ thidiazuron (TDZ). All experiments were conducted under dark conditions and $22 / 16{ }^{\circ} \mathrm{C}(8 / 16 \mathrm{~h})$ temperature cycle. The micro tuberization performances were evaluated according to MT number per plant, MT formation rate (\%), MT weight per plant (g), mean MT weight (g), mean MT diameter $(\mathrm{mm})$. Differences between micro tuber production performances of different genotypes were determined and CIP395017.229 was identified as the most promising genotype to produce micro tubers.
\end{abstract}

\section{Introduction}

Potato (Solanum tuberosum L.), a very important industrial crop, holds the fourth rank in crop production following maize, wheat and rice with approximately 390 million tones production in the world (FAOSTAT, 2014). Only a very small portion, (about $15 \%$ ) is considered for seed purpose in Turkey (Çalışkan et al., 2010). The lack of certified potato seed tuber production forces the farmers to produce their own seed tubers or provide noncertified potato seed tubers. This threatens the sustainability of Turkish potato production as it causes the spread of many disease agents as well as low yield and quality.

Mini tuber production is considered as one of main propagation methods for potato seed tuber in recent years (Struik, 2007; van Loon, 2007; Çalışkan et. al., 2014a). Mini tuber production is started with in vitro potato plant production and transferring these plants to the greenhouses with different techniques, including production of very small tubers called as micro tubers (van Loon, 2007; Sharma et. al., 2007; Ranalli, 2007). Micro tuber is a mid-stage between in vitro plant and mini tuber production. It is aimed to decrease the adaptation, transfer and storage problems of in vitro plants and increase the mini tuber number per plant through micro tuber production (Ranalli et al., 1997; Ranalli, 2007; Struik and Wiersema, 1999). Different parameters could affect micro tuber production performance of in vitro plants. These parameters can be listed as growth regulators, temperature, light and genotype (Kumlay et al., 2014; Dobronzski, 1997; Markorov et al., 1993; Gopol et al., 1998; Ranalli et al., 1994; Levy et al., 1993). All of them, except genotype, can be controlled under laboratory conditions. Thus, genotype effect on production is still a big concern. Several studies have claimed that genotype is closely correlated with the number and diameter of micro tubers (Karacsonyi et al. 2010).

The study aims to determine the genotype effect on micro tuber production by examining MT production performances of 15 different potato genotypes. In order to conduct the study standard varieties and breeding lines have been selected. A whole plant with 4 nodes was used as explant and all plants were grown on MS medium containing $8 \%$ sucrose and $0.1 \mathrm{mg} / \mathrm{L}$ TDZ for 2 months. Two months later, the tubers were harvested and the differences between the genotypes were determined. In conclusion, the micro tuber production was strongly correlated with genetic background. 


\section{Materials and Methods}

All experiments were performed in Omer Halisdemir University, Faculty of Agricultural Sciences and Technologies, Nigde, Turkey. Fifteen different potato genotypes were selected for the study. Hermes, Marabel and Sante, the standard varieties, were collected from Doğa Seed, Turkey; CIP300135.14, CIP389746.2, CIP392639.34, CIP392821.1, CIP393079.24, CIP395017.229, CIP398180.612, CIP398190.615, CIP399053.15 lines were collected from International Potato Center, Peru as in vitro plantlets, and MEÇ0601.02, MEÇ0601.24 MEÇ0908.12 were breeding lines developed in our breeding program. The sprout tips of healthy tubers of the breeding lines were used as initial explants, and surface sterilization of sprouts was performed by dipping in $70 \%$ ethanol for 1 minute, and then in $0.5 \%$ sodium hypochlorite for 8 minutes. Then, the explants were rinsed with sterile distilled water and transferred to MS medium supplemented with 3\% sucrose, $0.7 \%$ plant agar, $1 \mathrm{mg} / \mathrm{L}$ Kinetin, $1 \mathrm{mg} / \mathrm{L}$ IAA and $1 \mathrm{mg} / \mathrm{L} \mathrm{GA}_{3}$. After the shoot formation was observed within 15 days, the explants were transferred to MS0 medium without growth regulators to induce complete plant development. All genotypes were propagated by nodal culture on MS0 medium, which contains only $3 \%$ sucrose and $0.7 \%$ plant agar. For nodal culture, plants were grown under long-day conditions (16 h day/ $8 \mathrm{~h}$ night) and $25 / 16^{\circ} \mathrm{C}$ temperature cycle in growth chamber.

In order to obtain micro tuberization, liquid MS medium with $8 \%$ sucrose and $0.1 \mathrm{mg} / \mathrm{L} \mathrm{TDZ}$ were used.
A cotton layer was placed on the base of plastic containers and containers were autoclaved with cotton inside. Following, TDZ was added through sterile filter to formerly autoclaved MS medium. The medium was poured to containers under sterile conditions. Whole plants with four nodes were used as explants, and plants were placed on the cotton layer horizontally. Each container had 10 plants, and the experiment was repeated 5 times for each genotype. Plants were grown under dark conditions and $22 / 16^{\circ} \mathrm{C}(8 / 16 \mathrm{~h})$ temperature cycle for 2 months. The micro tuberization performances were evaluated according to MT formation rate, MT number per plant, MT weight per plant, mean MT weight and mean MT diameter. The obtained data were subjected to variance analysis according to randomized trial design using SAS statistical program. The differences of means were compared at the level of 5\% using LSD test.

\section{Results}

The effect of genotype on micro tuberization was determined by this study. Although all genotypes were exposed to same conditions, their micro tuber production performance rates were highly different. For all genotypes, the micro tuber formation was observed within 3 weeks. However, the quality and yield varied among genotypes.

The quantitative and physiological results of the study is given in details below, and alongside of overall appearance of plants, the shape and sizes of micro tubers were presented in Figure 1.

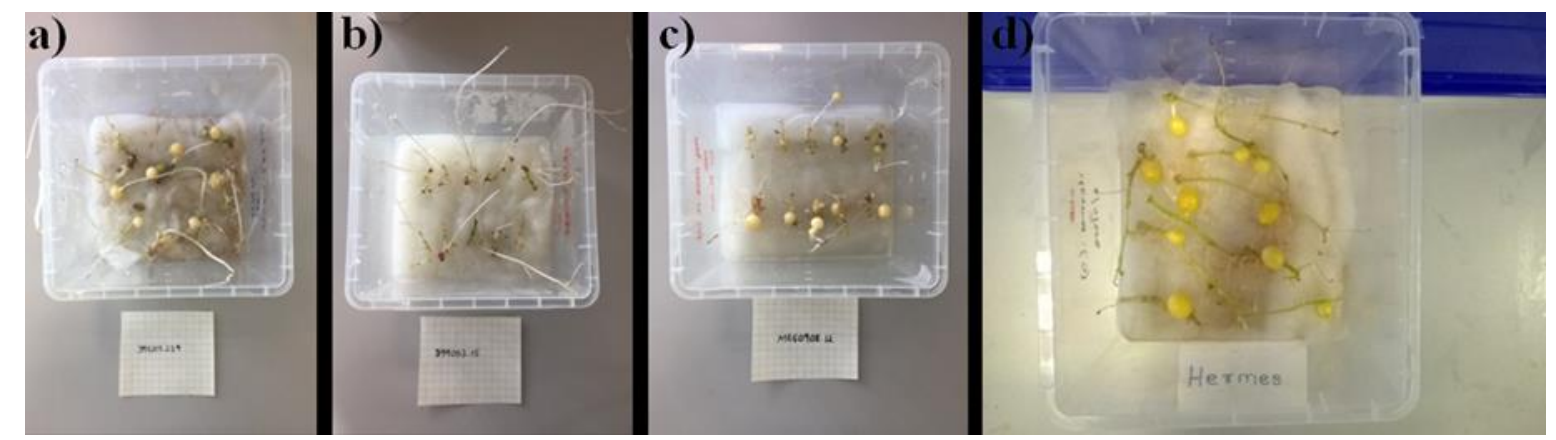

Figure 1 Micro tuber production of several genotypes. a) 395017.229, b) 399053.15, c) MEÇ0908.12, d) Hermes

\section{Quantitative Analysis of Micro Tuberization}

The micro tuber formation rate was calculated by number of microtuber per plant of each genotype. The micro tuber formation rate of the genotypes is given in Figure 2a. The mean MT formation rate is 66.09 of all genotypes. The genotypes with $10 \%$ higher of mean MT formation rate was evaluated as having high performance. Within this framework, 300135.14, 395017.229, 398180.612, 398190.615, Hermes and MEÇ0908.12 were classified as genotypes with high performance. The rest genotypes were out of this range, and showed medium and low performances. The harvest results were shown at Figure 3 for few genotypes.
Another parameter that shows the micro tuber production performances of potato genotypes is micro tuber number per plant. All genotypes produced roughly 1 tuber per plant except CIP399053.15, with 0.1 tuber. The MT number per plant was given in Figure $2 b$.

\section{Physiological Analysis of Micro Tuberization}

The second part of the study is the evaluation of tubers according to their sizes and weight. For this purpose, total weight of the tubers and diameter of each tuber were measured. 
a)

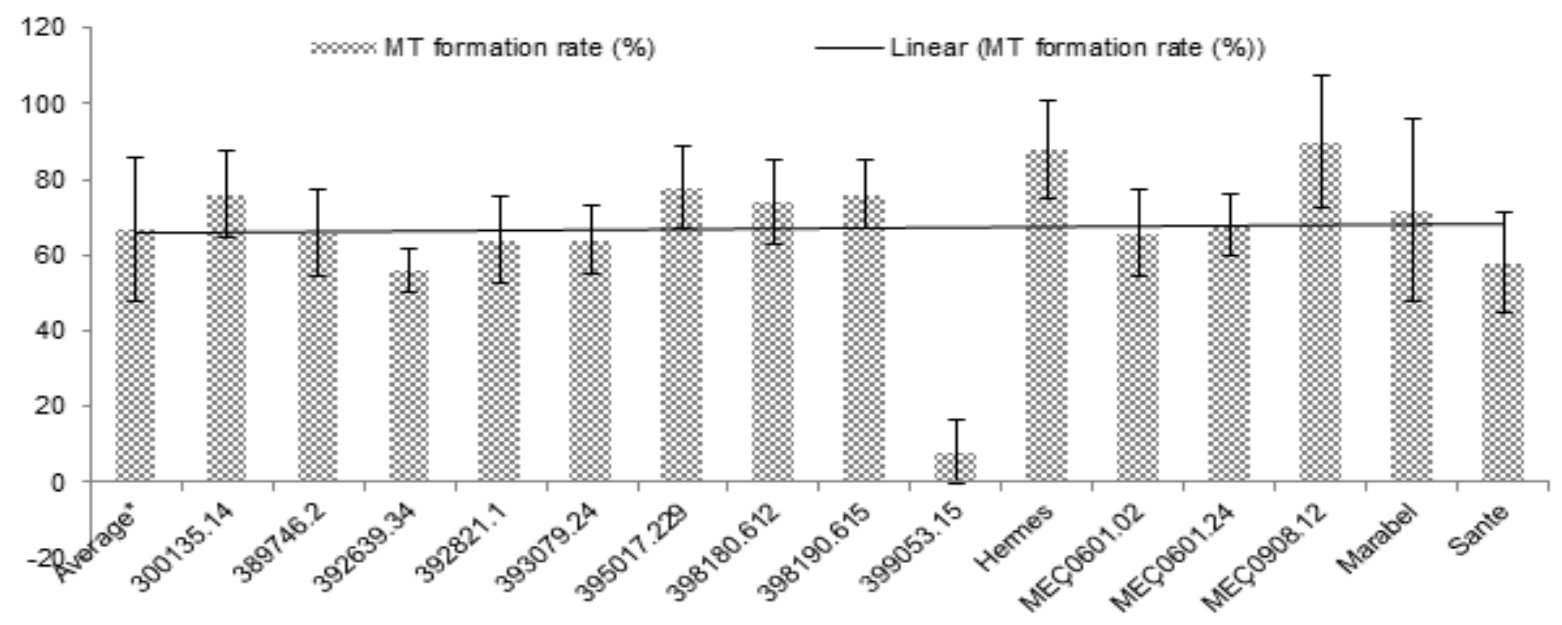

b)

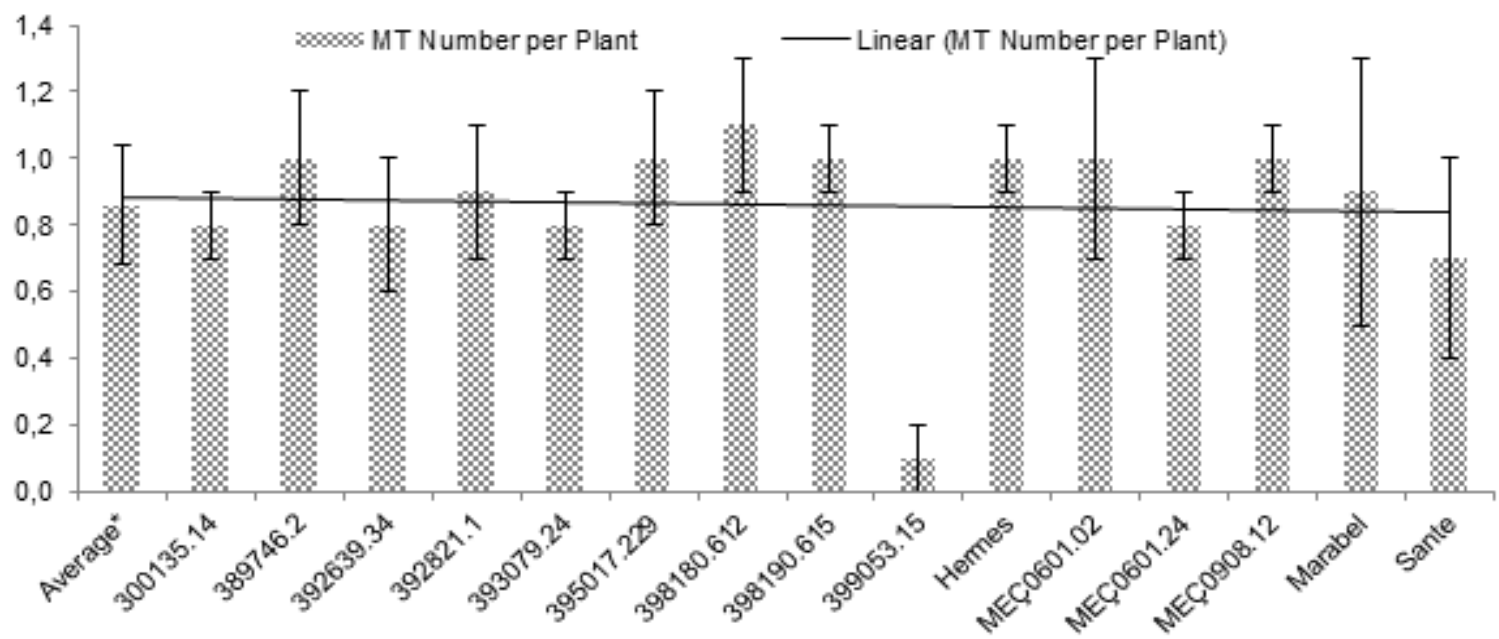

c)

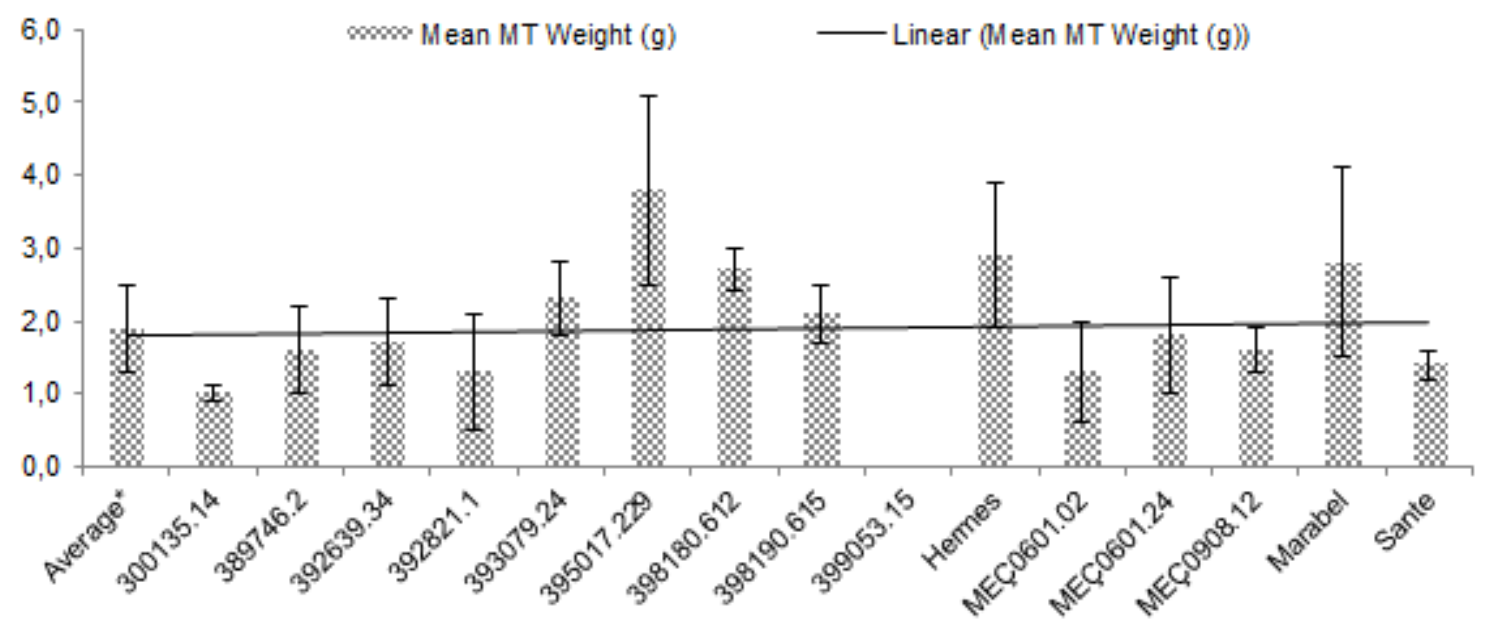


d)

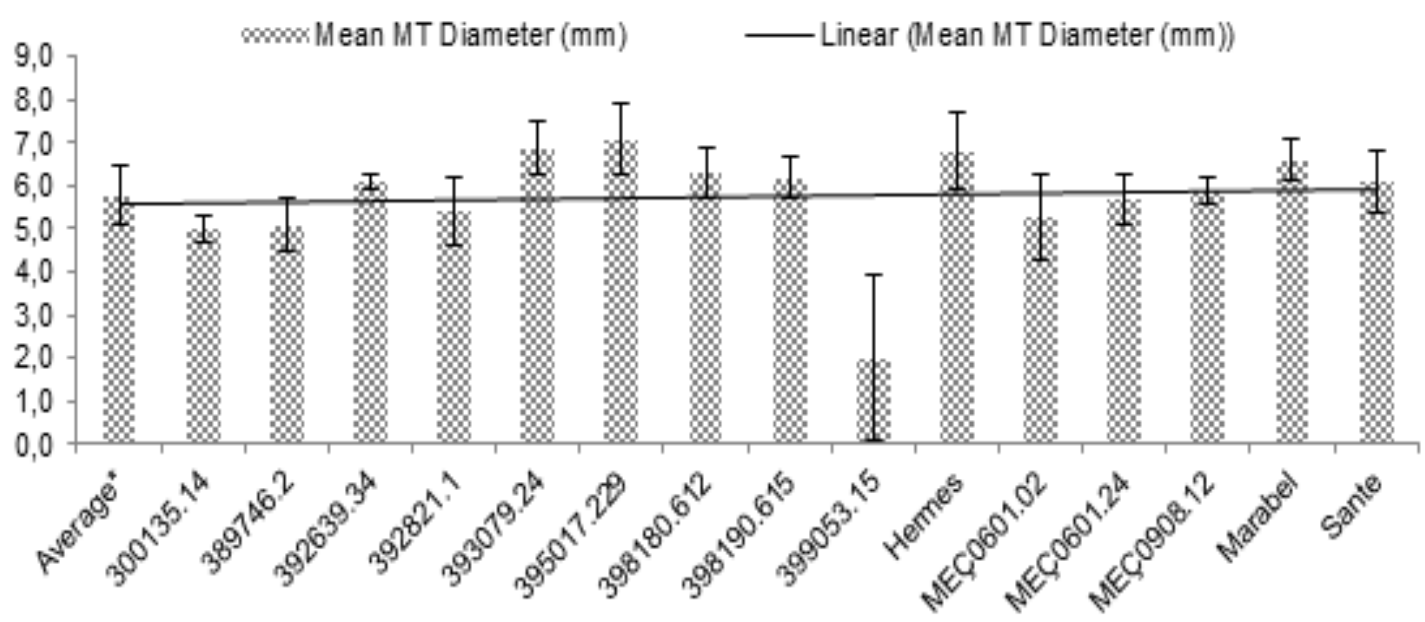

e)

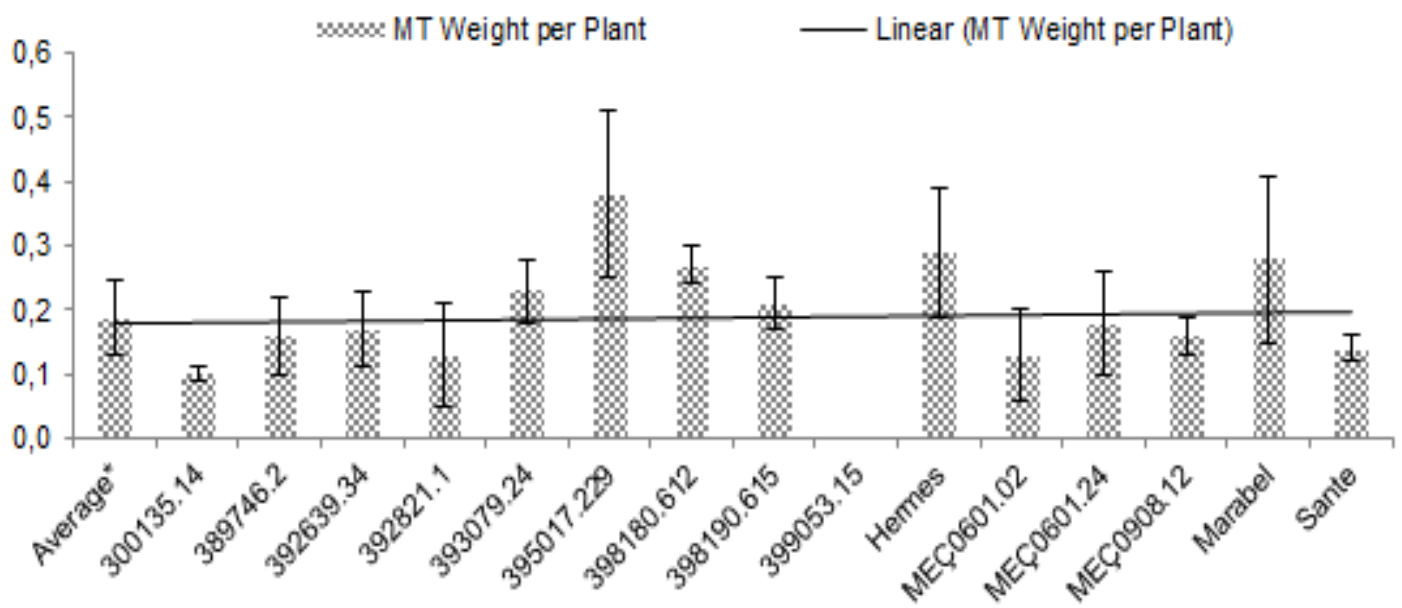

Figure 2 a) MT formation rate (\%), b) MT number per plant, c) Mean MT weight (g), d) Mean MT diameter (mm), e)MT weight per plant.

Regarding to these data, mean micro tuber weight fluctuates between $0.1 \quad(\mathrm{CIP} 399053.15)$ to 0.38 (CIP395017.229) g. $0.21 \mathrm{~g}$ was average value for all mean micro tuber weight for all genotypes. Genotypes scored higher than $10 \%$ of mean value, $0.21 \mathrm{~g}$ were 393079.24 , 395017.229, 398180.612, Hermes and Marabel indicating higher mean micro tuber weight than optimal. The result was given at Figure 2c. The diameter of microtubers varied between 2.0 (CIP399053.15) to 7.1 (CIP395017.229) mm. 393079.24, 395017.229, Hermes and Marabel were the genotypes scoring $10 \%$ higher of average value for all genotypes, 6.38 as shown in Figure 2d.

The least and the highest value for MTweight per plant are 0.1 and 0.38 with very exceptional value, 0 , for 399053.15 as given in Figure 2e. Overall, CIP395017.229 showed the best micro tuberization performance; however, CIP399053.15 showed the worst.
The correlation between MT formation rate, mean MT weight and mean MT ratio is given in Table 1. All correlations were found to be significant $(p<0.001)$.Table 1 shows that higher MT number also induced heavier and larger micro tubers. Besides, the larger micro tubers were also heavier.

\section{Conclusion}

The genotype effect on in vitro micro tuberization was clearly observed by this study. Micro tubers were successfully produced in 15 genotypes under same conditions with large micro tuber number and size range. The study shows that, the micro tuber production performances is associated with genetic background of potatoes and production of high number tubers come with larger and heavier tuber. 


\section{Acknowledgement}

This study was funded by Omer Halisdemir University Research Projects Unit Project No FEB 2015/15 BAGEP. We thank TUBITAK for providing Ph.D. scholarship to Sarbesh Das Dangol.

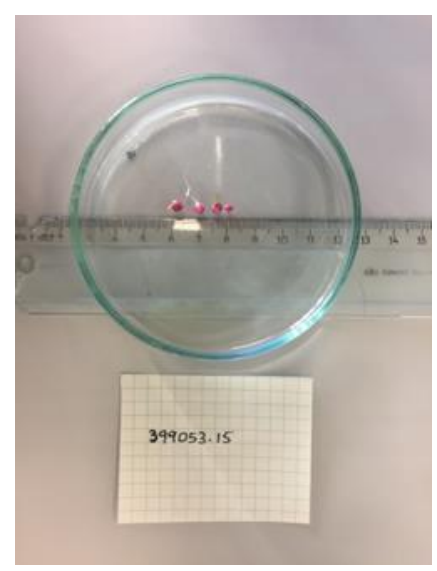

a

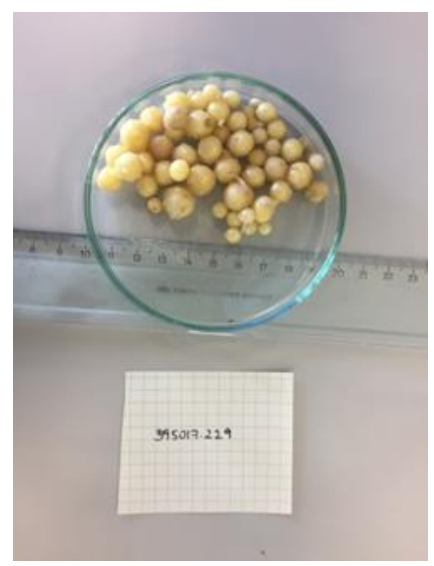

c

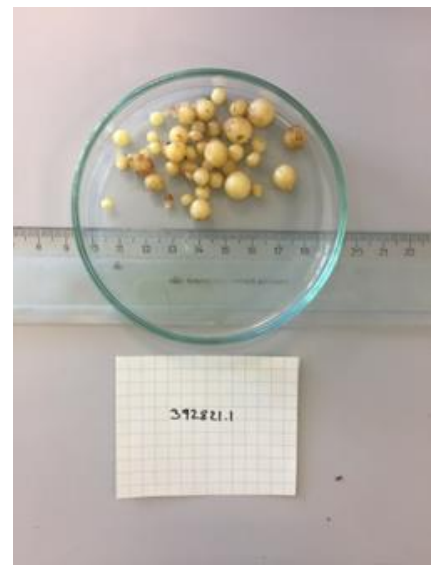

Figure 3 Harvest output of a) 399053.15, b) MEÇ0908.12,

\section{References}

Çalışkan ME. 2014. Türkiye'de patates üretimi ve patates politikamız. TÜRKTOB Dergisi, 10: 18.

Çalışkan ME, Onaran H, Arığlu H. 2010. Overview of the Turkish Potato Sector: Challenges, Achievements and Expectations. Potato Research, 53: 255-266.

Dobranszki J. 1997. Effects of dark treatment on tuber initiation and development of induced potato plantlets cultured in vitro. Acta Agron Hung, 44: 377-386.

FAOSTAT. 2017. http://www.fao.org/faostat/en/\#home

Gopal J, Minocha JL, Dhaliwal HS. 1998. Micro tuberization in potato (Solanum tuberosum L.). Plant Cell Reports. 17: 794798.

Kumlay AM, Arslan N, Kaya C. 2014. Farklı fotoperiyot şartlarında in vitro olarak yetiștirilen patates (Solanum tuberosum) eksplantlarına bitki büyüme düzenleyicilerinin etkileri. Iğdır Üni. Fen Bilimleri Enst. Der. 4: 83-94.

Levy D, Seabrook JEA, Coleman S. 1993. Enhancement of tuberization of axillary shoot buds of potato (Solanum tuberosum L.) cultivars cultured in vitro. J Expt Botany. 44: 381-386.

Markarov AM, Golovko TK, Tabalenkova GN. 1993. Photoperiodic responses in the morphological and functional characteristics of three potato species. Soviet Plant Physiol. 40: 32-36.

Ranalli P. 1997. Innovative propagation methods on seed tuber multiplication programmes, Potato Res. 40: 439-53.

Ranalli P. 2007. The Canon of Potato Science: 24. Microtubers. Potato Res. 50: 301-304.

Ranalli P, Bizarri M, Borghi L, Mari M. 1994. Genotypic influence on in vitro induction, dormancy length, advancing age and agronomical performance of potato microtubers (Solanum tuberosum ). Ann Appl Biol. 125: 93-01.

Sharma SK, Bryan GJ, Winfield MO, Millam S. 2007. Stability of potato (Solanum tuberosum L.) plants regenerated via somatic embryos, axillary bud proliferated shoots, microtubers and true potato seeds: a comparative phenotypic, cytogenetic and molecular assessment. Planta 226:1449-1458.

Struik PC, Wiersema SG. 1999. Seed Potato Technology. Wageningen Pers, Wageningen.

Struik PC. 2007. The Canon of Potato Science: 25. Minitubers. Potato Res. 50: 305-308.

van Loon KD. 2007 The seed potato market (Ed. D. Vreugdenhil) Potato Biology and Biotechnology, Advances and Perspectives. Amsterdam: Elsevier. pp: 45-52 